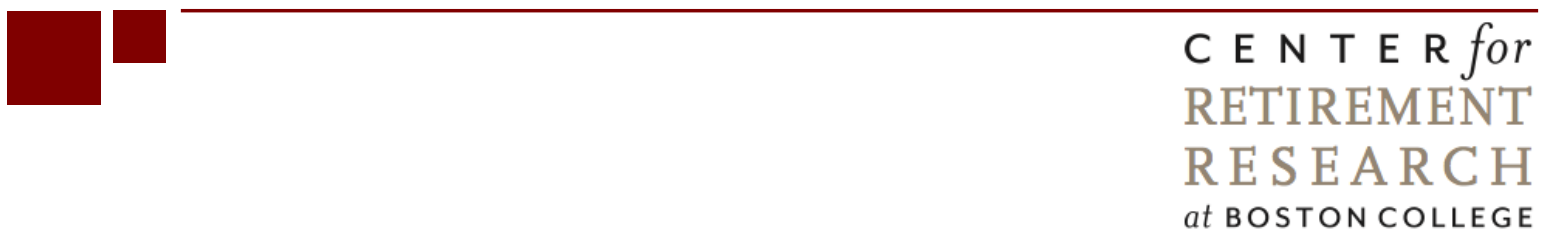

\title{
HOLDING OUT OR OPTING OUT? DECIDING BETWEEN RETIREMENT AND DISABILITY APPLICATIONS IN RECESSIONS
}

\author{
Matthew S. Rutledge \\ CRR WP 2012-26 \\ Submitted: October 2012 \\ Released: November 2012 \\ Center for Retirement Research at Boston College \\ Hovey House \\ 140 Commonwealth Avenue \\ Chestnut Hill, MA 02467 \\ Tel: 617-552-1762 Fax: 617-552-0191 \\ http://crr.bc.edu
}

Matthew S. Rutledge is a research economist at the Center for Retirement Research at Boston College. The research reported herein was pursuant to a grant from the U.S. Social Security Administration (SSA), funded as part of the Retirement Research Consortium (RRC). The research in this paper was conducted while the author was a Special Sworn Status researcher of the U.S. Census Bureau at the Boston Census Research Data Center. All results have been reviewed to ensure that no confidential information is disclosed. The findings and conclusions expressed are solely those of the author and do not represent the views of SSA, any agency of the federal government, the RRC, the U.S. Census Bureau, the Boston Census Research Data Center, or Boston College. The author would like to thank Norma B. Coe, Kathleen Mullen, Philip Armour, Martha Stinson, and seminar participants at the Retirement Research Consortium conference and the Census RDC conference for helpful comments.

(C) 2012, Matthew S. Rutledge. All rights reserved. Short sections of text, not to exceed two paragraphs, may be quoted without explicit permission provided that full credit, including (c) notice, is given to the source. 


\title{
About the Center for Retirement Research
}

The Center for Retirement Research at Boston College, part of a consortium that includes parallel centers at the University of Michigan and the National Bureau of Economic Research, was established in 1998 through a grant from the Social Security Administration. The Center's mission is to produce first-class research and forge a strong link between the academic community and decision-makers in the public and private sectors around an issue of critical importance to the nation's future. To achieve this mission, the Center sponsors a wide variety of research projects, transmits new findings to a broad audience, trains new scholars, and broadens access to valuable data sources.

\author{
Center for Retirement Research at Boston College \\ Hovey House \\ 140 Commonwealth Avenue \\ Chestnut Hill, MA 02467 \\ phone: 617-552-1762 fax: 617-552-0191 \\ e-mail: crr@bc.edu \\ crr.bc.edu
}

Affiliated Institutions:

The Brookings Institution

Massachusetts Institute of Technology

Syracuse University

Urban Institute 


\begin{abstract}
Workers over age 55 with chronic health conditions must choose between applying for Social Security Disability Insurance (SSDI) benefits or continuing to work until their Social Security retirement benefits become available. Previous research has investigated the influence of macroeconomic conditions on disability application and, separately, on retirement claiming. This project uses data from the Survey of Income and Program Participation Gold Standard File to determine whether there is a relationship between national and state unemployment rates and disability applications, taking into account the current or future receipt of Social Security retirement benefits. First, reduced-form estimates indicate that retirement beneficiaries are more likely to apply for SSDI as unemployment increases - and, conversely, eligible individuals who have not yet claimed benefits are less likely to apply when unemployment rises. But after accounting for unobserved characteristics associated with both the decision to apply for disability insurance and Social Security benefits, individuals are no more likely to apply for disability benefits when unemployment is high. Second, we find that the probability of SSDI application among individuals age 55-61 is unrelated to macroeconomic conditions and unrelated to proximity to one's $62^{\text {nd }}$ birthday. These results suggest that, unlike prime-age adults, the decision among older individuals to apply for disability is based primarily on health, and not financial incentives.
\end{abstract}




\section{Introduction}

Working adults age 55 and older with chronic health conditions are often faced with a difficult choice. Behind Door Number One: keep working as long as possible and claim Social Security benefits when they are available, either on their $62^{\text {nd }}$ birthdays, or later if they have alternative sources of income to finance consumption. Behind Door Number Two: apply for benefits from Social Security Disability Insurance (SSDI), and, if income and wealth are low enough, also apply for Supplemental Security Income (SSI). ${ }^{1}$ Both options have their upsides but also substantial drawbacks. By remaining in the workforce and "holding out" for retirement benefits later, the individual likely raises his eventual benefit level, possibly accumulates assets for his retirement years, and maintains his connection to working society. But doing so may increase stress and worsen his health, and jobs that accommodate his chronic conditions may be hard to find and retain. "Opting out” of the workforce by applying for SSDI benefits locks in a monthly benefit level, allows for more time to address health issues, and includes access to Medicare coverage after a two-year waiting period, rather than having to wait until age 65. But disability application is uncertain and carries substantial costs: time, effort, pecuniary, and emotional. Even when their applications are successful, disability beneficiaries lose out on further asset accumulation or the opportunity to increase Social Security benefits, so the income levels they are locking in for life are likely to be low.

Further complicating any analysis, the incentives to apply to SSDI change when the potential applicant is already eligible for, or receiving, Social Security retirement benefits. Individuals age 62 or older can more easily drop out of the labor force and make ends meet while waiting for their SSDI determination, relying on their retirement benefits as a backstop. If the individual claimed Social Security retirement benefits before his Full Retirement Age (FRA) 65 for most cohorts in this study - his benefits are reduced to reflect the extra years he will receive funds from Social Security. Applying to SSDI successfully restores full benefits, increasing his monthly Social Security income by as much as 30 percent from his reduced level. If SSDI application costs are low, this suggests that SSDI application becomes more attractive after age 62, even without earlier access to Medicare (Benitez-Silva and Yin 2011).

\footnotetext{
${ }^{1}$ Much of the discussion in the introduction and conceptual framework sections of this paper focuses on individuals who have accumulated enough work experience to be "insured" for SSDI. The econometric analysis includes any application to a public disability program, including SSI-only, but does not consider SSI application separately from SSDI application because of small sample size.
} 
Labor market conditions directly and indirectly affect most of the pros and cons when weighing disability application, retirement claiming, or continued workforce participation. When unemployment rates are high, the near-elderly worker himself, or a family member upon whom he counts for support, is more likely to lose a job, and less likely to find a new one. Declines in financial markets may deplete the assets available to cushion income shocks. Longterm structural shifts may change the physical demands of both his current job and those available to him. Recessions also may narrow his health insurance options - through job loss, changes to retiree benefits, or cutbacks in public coverage - and directly influence his health. ${ }^{2}$

This paper estimates the influence of national and state unemployment rates on the decision to apply for public disability benefits, conditional on the current, or imminent, availability of Social Security retirement benefits. The estimation uses the Survey of Income and Program Participation (SIPP) Gold Standard File, which links Social Security administrative data on disability application and Social Security benefit receipt to demographics and labor market activity from the SIPP household survey. Reduced form estimates indicate that retirement beneficiaries are more likely to apply to SSDI or SSI than age-eligible individuals who have not yet claimed Social Security, and that applications are more likely from retirement beneficiaries and less likely from eligible non-recipients when the unemployment rate is higher. However, after accounting for unobservable factors that influence both retirement benefit claiming and disability application, retirement beneficiaries are actually less likely to apply to SSDI or SSI, and application rates appear to be unrelated to labor market conditions. Similarly, there is little evidence of a relationship between the unemployment rate and SSDI application for individuals age 55 to 61, nor do applications become significantly less likely, as had been expected, as an individual gets closer to his $62^{\text {nd }}$ birthday.

A rich literature has found that disability applications increase with the unemployment rate; Autor and Duggan (2006) provide a survey of past research. Other studies find that rising unemployment rates increase retirement rates (Coile and Levine 2007; Von Wachter 2007; Hallberg 2008; Friedberg et al. 2008; Munnell et al. 2008) and increase Social Security retirement benefit claiming (Coile and Levine 2011; Rutledge and Coe 2012).

\footnotetext{
${ }^{2}$ The stress of a job loss or asset declines could have a deleterious effect on health; Sullivan and von Wachter (2009) find mortality effects lasting two decades after a job loss. Ruhm (2000), however, shows that recessions have positive effects on mortality, though Stevens et al. (2011) contend that this has little to do with one's own behavior (except, as Ruhm (2000) finds, for fewer car accident fatalities), and is mostly due to better staffing in nursing homes.
} 
Despite the interrelated nature of the decisions to retire, to claim Social Security retirement benefits, and to apply for public disability benefits, however, few existing studies model this joint decision. And of the few that do, none focuses on the influence of macroeconomic conditions on near-elderly Americans’ joint decisions in a unified framework. Both Chirikos and Nestel (1991) and Hayward et al. (1989) focus on how occupation affects the decision. Riphahn (1997; 1999) rejects claims that applicants to the German disability retirement program as supplemental unemployment insurance. Bound, Stinebrickner, and Waidmann (2010) focus on the effects of health on these decisions, modeling the SSDI vs. retirement decision using a dynamic programming model. Benitez-Silva and Yin (2011), using a life-cycle structural model of disability application, find that potential disability applicants who are eligible for Social Security retirement benefits are more responsive to potential benefits and award probabilities than are younger workers.

Only Dahl, Nilsen, and Vaage (2000) appear to include local unemployment rates as an explanatory variable; they find a weak statistical relationship between disability application and local labor market conditions, but a stronger and substantial relationship between unemployment rates and retirement. It is unclear, however, whether their results for Norwegian workers in the early 1990s would apply to current U.S. workers.

This paper fills a gap in the literature by examining the effects of national and state labor market conditions on the joint labor force exit, retirement benefit claiming, and disability application decisions among Americans age 55 and older. The estimation model also allows for the unemployment rate to have a differential effect before and after Social Security retirement benefit eligibility, and accounts for the endogeneity of retirement benefit claiming. Finally, this study investigates whether the decision to apply for disability is a function of the months remaining until one becomes eligible for Social Security retirement benefits.

The structure of this paper is as follows. Section 2 details the institutional background for the three interrelated Social Security programs. Section 3 outlines a conceptual framework yielding testable empirical predictions. Section 4 describes the SIPP Gold Standard File data and the sample selection criteria. Section 5 outlines the empirical model, and Section 6 presents its results. Section 7 discusses the potential implications of acylicality in the disability application rate among older Americans. 


\section{Institutional Background}

The Social Security Administration is responsible for administering three programs that pay cash benefits to older or impaired workers.

Social Security Retirement Benefits. The most prominent of the three programs - and the one most commonly associated with Social Security - is the Old Age and Survivors Insurance (OASI) program, which pays a monthly annuity to retirees. Workers are eligible for OASI if they have accumulated 40 quarters of covered employment, or "credits," during their careers. ${ }^{3}$ The worker earns a credit when his eligible earnings reach a multiple of a year-specific dollar figure (\$1,130 in 2012), up to a maximum of four credits per year. ${ }^{4}$

Individuals can start receiving benefits as soon as the month of their $62^{\text {nd }}$ birthday, which is the Early Eligibility Age (EEA). The benefit level is adjusted to be actuarially fair - that is, expected lifetime benefits are equal no matter when benefits are first claimed - so that benefits grow with each additional month the beneficiary delays his start.

The benefit level is calculated in a multistep process. First, SSA adjusts each year's earnings for inflation, based on the Average Wage Index. SSA then determines the beneficiary's highest 35 years of earnings, including zero-earning years. The Average Indexed Monthly Earnings (AIME) is the sum of the top 35 years of inflation-adjusted earnings divided by 420 (35 years times 12 months). The Primary Insurance Amount (PIA), the level of benefits for which the individual is eligible at Full Retirement Age (FRA), is a progressive function of the AIME: 90 cents on the dollar at first (up to \$767 in 2012), then 35 cents on the dollar (up to \$4,624 in 2012), and 10 cents on the dollar thereafter. Finally, the benefit level is permanently adjusted: downward for those who claim benefits before FRA, and upward for those who delay claiming until after FRA (up until the $70^{\text {th }}$ birthday).

The FRA varies based on one's birth cohort. Cohorts born before 1938 reach FRA at their $65^{\text {th }}$ birthdays. The FRA increases by two months for each cohort born between 1938 and 1943, so that the FRA is age 66 for the 1943-1954 cohorts. The FRA is scheduled to increase by another two months for each cohort between 1955 and 1960, up to age 67. As a result, the

\footnotetext{
${ }^{3}$ No credits are earned during one’s employment in certain industries that are Social Security exempt, including some state and local workers and railroad employees, graduate students, and nonresident aliens.

${ }^{4}$ Before 1978, an individual could earn a credit for each quarter with at least $\$ 50$ of earnings, or four credits for $\$ 400$ or more over the full year. Starting in 1978, SSA began requiring only annual earnings reports, rather than quarterly.
} 
actuarial adjustment downward is larger for those who claim benefits before FRA in later cohorts, and the adjustment upward is smaller for those claiming after FRA.

Most beneficiaries claim Social Security retirement benefits only after or at the same time that they leave the labor force, though some continue or return to work after claiming. Social Security benefits are reduced by 50 cents for each dollar earned over the "earnings test," set at $\$ 14,640$ in 2012, for income earned before the beneficiary’s FRA, though the reduced benefits are re-allocated to the beneficiary after FRA. ${ }^{5}$

Social Security Disability Insurance. SSDI has many of the same parameters as OASI but is meant for those who are unable to work for at least a year due to a physical or mental impairment. An individual is SSDI-insured if he has accumulated a certain number of credits over his career, with the number of required career credits increasing with age (between 20 and 40 required credits, with the number required increasing by two every other year between ages 42 and 62), with 20 of those credits earned in the last ten years.

Individuals who earn less than the Substantial Gainful Activity (SGA) level (\$1,010 per month in 2012) can apply for SSDI benefits beginning five months after the onset of the disability. The Disability Determination Service in the applicant's state uses information from medical providers to decide whether the individual's medical condition is on the List of Impairments that trigger automatic acceptance, and if not, whether the applicant can do the same work he or she did before, and whether he or she can do any other type of work. Approximately 37 percent of SSDI applications are approved at the initial determination, according to the data used in the state-level regression. Wait times between application and initial determination average 131 days (SSA 2008), though the wait time is often longer for cases that are not listed impairments or terminal cases. Appeals may also lengthen the time before an ultimately successful applicant first receives benefits.

The SSDI benefit level is the PIA, based on the same formula as OASI, with no actuarial adjustment for age. Current OASI beneficiaries who started receiving actuarially reduced benefits can, therefore, increase their monthly benefit and restore their full PIA by successfully applying for SSDI; in fact, the application for OASI benefits includes a question about whether the claimant is disabled, and SSA is required to pursue all benefits for which the claimant may be

\footnotetext{
${ }^{5}$ Up until 2000, the earnings test applied to earnings up to one's $70^{\text {th }}$ birthday but now applies only to earnings before the FRA.
} 
eligible, so OASI and SSDI often have a mechanical relationship. SSDI beneficiaries are automatically transferred into the OASI program at their FRA, as they have no longer have an incentive to claim SSDI. In contrast to OASI, which sometimes sees beneficiaries switch to SSDI or suspend benefits due to workforce re-entry, few SSDI beneficiaries leave the rolls: less than 4 percent of the 1996 SSDI cohort had benefits terminated in the subsequent ten years for earning more than SGA (Stapleton, et al. 2008), so most leave the rolls only at FRA or death.

In addition to SSDI's cash benefits, beneficiaries are eligible for Medicare coverage 24 months after first being entitled to receive SSDI benefits. Since everyone is eligible for Medicare at age 65, someone age 63 or older applying to SSDI will derive no additional health insurance benefit; given the long wait times and the five-month waiting period, neither will most 62-year-olds.

Supplemental Security Income. Working-age individuals are eligible for SSI only if their income and wealth fall below eligibility thresholds and they satisfy the same disability screening as SSDI. To qualify, their countable income must be below the federal SSI benefit level. ${ }^{6}$ In addition, non-housing wealth must be below $\$ 2,000$. The individual can then receive the difference between the monthly benefit level of $\$ 674$ and the recipient's countable income. In addition, SSI recipients are eligible for Medicaid coverage as soon as they are approved for benefits.

SSI applicants are not required to work a minimum number of quarters, though many work-limited, low-income individuals with sufficient work experience apply concurrently to both SSDI and SSI. OASI recipients may also be eligible for SSI if their income, including retirement benefits, is low. ${ }^{7}$ Unlike SSDI, which can restore the full PIA for OASI recipients, there is no special incentive - beyond increased income - for OASI beneficiaries to apply to SSI.

\section{Conceptual Framework}

This study provides a simple model of decisions by utility-maximizing individuals to apply for SSDI or claim Social Security retirement benefits. This section makes four simplifying assumptions: (1) the representative individual between the ages of 55 and his FRA has accumulated enough total and recent work experience to be SSDI-insured immediately and

\footnotetext{
${ }^{6}$ Countable income excludes $\$ 20$ per month of non-labor income and, for workers, \$65 per month plus one-half of labor earnings beyond this level.

${ }^{7}$ Unlike earned income, OASI benefits reduce SSI benefits dollar-for-dollar (after the first \$20 per month).
} 
OASI-eligible when he reaches age 62; (2) the individual has levels of non-labor income and/or wealth that are too large for SSI, so the disability application decision is simply whether to apply to SSDI; (3) the individual is still working for pay but has health problems that are marginal enough that his disability onset date would be the present month if he left the labor force immediately, but severe enough that his probability of receiving benefits is greater than zero; and (4) once an individual claims retirement benefits, he earns less than SGA. Finally, his utility function is increasing and highly concave in his income, so that a drop in income after, say, a job loss induces him to seek out other sources to make ends meet.

This individual's decision differs substantially depending on whether he has reached age 62. First, consider a younger individual (age 55 to 61). In a given month, the individual chooses the option with the highest net present discounted utilities (the "value" of each option): that of leaving the labor force and claiming SSDI benefits, of applying for Social Security retirement benefits starting in the month of his expected retirement date, and of applying for Social Security retirement benefits starting in the month of his $62^{\text {nd }}$ birthday. The value he places on SSDI application accounts for both his perceived probability of being awarded benefits, which is greater for someone in worse health, and his application costs, which include the financial cost of visits to his care provider as well as time, effort, and psychic burdens. All three benefits begin with a lag. Obviously, he is comparing OASI receipt at two future dates, but he would begin to receive SSDI only after a five-month wait (with certainty). ${ }^{8}$ The value of each of the three benefits depends on his PIA, which increases while he is working; the increase is smaller for OASI starting at age 62, and greatest for SSDI if his expected retirement date is before his FRA.

When a recession hits, however, the values he places on these three benefits change in several ways. First, if he loses his job and is unable to find work quickly, his income decreases, causing his utility to fall precipitously in the current period. This makes immediate benefit application from SSDI more attractive. In addition, his PIA stops growing. While this slightly dampens his preference for SSDI (the immediate need for income still dominates), it mostly increases the relative attractiveness of claiming OASI at age 62 instead of delaying claiming. Furthermore, his ideal retirement age likely increases, as he considers that he needs to work

\footnotetext{
${ }^{8}$ In reality, the waiting time is unknown at any given time, as it depends on a number of factors, including the active caseload for SSDI examiners in that state. The five-month wait time assumption is chosen because new SSDI awardees do not receive benefits for the first five months after disability onset. Coincidentally, the average wait time from application to initial determination is 131 days, or just short of five months (SSA 2008).
} 
longer to recoup lost earnings during his jobless spell, presuming he does not get discouraged and leave the labor force sooner; a decision to delay retirement may reduce the present discounted utility of benefits, if the longer wait for benefits outweighs the increase in the benefit level (from working and/or from the actuarial adjustment).

An individual who does not lose his job in the recession may find SSDI application less attractive. First, he is more likely to cling to the job he has than to quit and take his chances with an uncertain result from his application - if he is unsuccessful, finding a new job would be difficult. Second, with the increasing number of SSDI applicants, his probability of being awarded benefits likely falls, and his waiting time almost certainly increases. ${ }^{9}$ Meanwhile, his expected retirement age likely increases, particularly if he is supporting a job-losing family member or has sustained losses in the financial market. Whether delaying an OASI claim becomes more or less attractive relative to an age-62 claim is unclear. He may not want to sacrifice a steady job to retire at age 62 if he feels his labor market exit would be hard to reverse, but previous literature suggests that early claiming increases in a recession, not just among those who lose their jobs (Rutledge and Coe 2012).

This discussion indicates that an increasing unemployment rate affects the SSDI application rate among 55- to 61-year-olds differently depending on whether the potential applicant is directly affected by the weakening labor market. Those who are unemployed will no longer hold out until age 62 (or their expected retirement age) and will increasingly apply to SSDI. Active workers are more likely to continue working, forgoing an SSDI application and holding out for Social Security retirement benefits at or after age 62. Holding out is more feasible the closer the potential applicant is to age 62, so the unemployed in their late-50s are more likely to apply to SSDI than 60- or 61-year-old unemployed individuals when the economy weakens. $^{10}$

The consequences of SSDI application are quite different for individuals between age 62 and their FRA. For them, claiming retirement benefits does not preclude them from applying to

\footnotetext{
${ }^{9}$ Strand (2002) finds that the state application rate is negatively correlated with that state's allowance rate.

${ }^{10}$ The SSDI application decision becomes slightly different when the individual is within about five months of his $62{ }^{\text {nd }}$ birthday. At this point, his choice set becomes more like that of someone who is already 62, because he is unlikely to start receiving SSDI benefits until after he would be able to claim OASI benefits. The situation is different with someone about to reach their FRA. If he has already claimed OASI benefits, he can increase his benefit by as much as 25 percent (if he was born before 1955) as long as he applies before his FRA. If he has not already claimed OASI benefits, he gains little from applying to SSDI and getting the full PIA versus claiming OASI and earning just slightly less than the PIA without incurring the application costs.
} 
SSDI. Unlike the pre-62 potential applicant, applications for SSDI and, eventually, OASI are not competing decisions. Someone who has already permanently left the labor force and claimed OASI benefits stands to gain by switching from the OASI to the SSDI program, thereby increasing his monthly benefit up to the full PIA. On the other hand, the concavity of the utility function with respect to income indicates that those who are already working and/or receiving Social Security retirement benefits increase their utility by much less than someone who is ineligible for OASI and has no other substantial source of income. Furthermore, costs, which may be substantial, remain relatively constant before and after age 62. Because most individuals after their $62^{\text {nd }}$ birthday are either working or receiving benefits, this project hypothesizes that older individuals are less likely to apply for SSDI benefits than are those under 62 .

When the unemployment rate increases, those who are still working past their $62^{\text {nd }}$ birthdays may prefer to keep working rather than apply to SSDI, especially if they sustained losses in the financial market. For those who have already retired and claimed OASI benefits, the effect of the increasing unemployment rate on the SSDI application decision is ambiguous: award probabilities fall and waiting times rise, but declining income from financial assets and increasing expenses from supporting family members may lead to a greater proportion of Social Security beneficiaries applying to SSDI.

In summary, among eligible individuals in their 50s and 60s, the most likely SSDI applicants are those who are furthest below age 62 and have lower incomes. OASI beneficiaries are also more likely to apply for SSDI benefits than those who are eligible for OASI but have not yet claimed - indeed, neglecting to claim OASI benefits suggests that the individual is still working or has alternative sources of income. When the unemployment rate rises, individuals who lose their jobs, particularly if they are under age 62, are more likely to apply to SSDI. Retained workers likely prefer to cling to their jobs rather than to cast their lot with an uncertain SSDI application. Finally, Social Security retirement beneficiaries may increase or decrease their application probability.

\section{Data}

The Survey of Income and Program Participation (SIPP) Gold Standard File is a composite data set, linking the SIPP household survey to Social Security administrative records on earnings and benefit claiming. 
SIPP samples U.S. households every four months for up to four years about their household and family structures and about individual household members' demographics, labor market activity, public program participation, and health insurance coverage. SIPP also periodically asks respondents about health status, assets and liabilities, and pension coverage. New panels began annually from 1984 to 1993, plus 1996, 2001, 2004, and 2008.

The SIPP Gold Standard File standardizes a subset of variables from the full SIPP across the 1984 and 1990-2008 panels, and it links SIPP individual data to administrative records using respondents' Social Security numbers. Of the 777,000 individuals in these SIPP panels, 579,000 have valid matches to Social Security data.

This project uses several pieces of data from the Social Security administrative records of SIPP respondents. The outcome variable for the analysis is the date of each individual's application to SSDI or SSI, deriving from the 831 File, which includes information on the timing and determination of each disability application. The date of Social Security retirement claiming derives from the Master Beneficiary Record, which includes information on benefit eligibility for Social Security programs. This project also calculates potential Social Security retirement and disability benefits and insurance status from the Summary Earnings Record and includes prior year's earnings as a control, using information from the Detailed Earnings Record.

Besides whether the individual is income- and age-eligible for SSDI and/or Social Security retirement benefits, the other two key explanatory variables in this analysis are the national and state unemployment rates obtained from the Bureau of Labor Statistics. In both instances, this project uses monthly rates that are not seasonally adjusted; the disability application rate itself exhibits seasonal patterns (Rutledge 2012), which suggest that liquidityconstrained potential applicants respond to predictable fluctuations in labor market conditions.

The sample includes SIPP respondents successfully matched to SSA records who are surveyed between their $55^{\text {th }}$ and $62^{\text {nd }}$ birthdays. Table 1 details the sample selection criteria. The sample excludes anyone who had already successfully applied to SSDI or SSI before becoming "at risk" - that is, before they reached age 55 or entered SIPP. The regression sample also requires that the individual is eligible for OASI benefits as well as either SSDI or SSI. The final sample for the hazard to any disability application includes just over 29,840 older individuals for the regression where the outcome is application to either SSDI or SSI, and 29,183 individuals for the SSDI application regression. 


\section{Empirical Strategy}

The decision to apply for public disability insurance benefits is modeled in several different hazard-model frameworks, depending on Social Security retirement eligibility: one for all months between age 55 and one's FRA, another just for months before one turns 62, and another just for months after one turns 62.

In the hazard model that includes all months, the probability of individual $i$ applying to SSDI or SSI in a given month $t, A_{i t}$, is a function of the resources available to the potential applicant at that time, including his Social Security retirement benefits and potential labor market income. Because the outcome variable is dichotomous and only the month of application is known, this discrete-time hazard is estimated using a probit regression model:

$$
\begin{aligned}
A_{i t}=\Phi\left(\beta_{1}{\text { Under } 62_{i t}+\beta_{2} \text { OASIRec }_{i t}+\beta_{3} \text { OASIElig }_{i t}+\beta_{U 1} \text { URate }_{t}}\right. \\
\left.\times{\text { Under } 62_{i t}+\beta_{U 2} \text { URate }_{t} \times \text { OASIRec }_{i t}+\beta_{U 3} \text { URate }_{t}} \times \text { OASIElig }_{i t}+\gamma X_{i t}+f\left(\tau_{t}\right)+\varepsilon_{i t}\right)
\end{aligned}
$$

where $\Phi$ represents the standard normal distribution. The unit of observation is the personmonth between becoming "at risk" at the earlier of $i$ 's $55^{\text {th }}$ birthday or entry into the SIPP sample and either "failure" - i.e., disability application - or censoring. In separate specifications, the outcome variable is application to SSDI, or either SSDI or SSI (without specifying which program). ${ }^{11}$

The key variables are the availability of other income sources and their interactions. The unemployment rate, URate, is a proxy for potential labor market income; different specifications of the model include the national and/or state unemployment rates. The three Social Security retirement indicator variables are mutually exclusive and exhaustive (hence, no constant or URate without interactions): Under62 is equal to one if the respondent is younger than 62 in month $t$, OASIRec is equal to one if the respondent receives Social Security retirement benefits by month $t$, and OASIElig is equal to one if the respondent is eligible for these benefits but has

\footnotetext{
${ }^{11}$ Too few older SIPP respondents apply to SSI without also applying to SSDI to analyze SSI-only applications separately. The analysis also makes no distinction between concurrent applications (applying for SSDI and SSI in the same month) and applications to one program at a time.
} 
not yet started receiving them by month $t .^{12}$ Work status is known only while the individual is in the SIPP, so the empirical model is not able to separate those who lose their job from those who retain it (or worked sporadically), though the conceptual framework predicts these groups may react to increasing unemployment rates differently. However, matrix $X$ does include work status as of the first SIPP interview, which captures some of this difference for months before age 62, and OASIElig captures much of the effect after the $62^{\text {nd }}$ birthday.

The conceptual framework suggests that eligible individuals who have not yet claimed their Social Security benefits are less likely to apply for SSDI or SSI benefits than are OASIineligible individuals (abusing notation slightly, $\beta_{3}<\beta_{1}$ ), since non-applicants still have a source of income readily available that has no application costs or waiting time. Those who are already receiving benefits may be more or less likely than ineligible individuals; the sign of $\beta_{2}$ suggests whether the benefit of applying to SSDI - receiving the full PIA - outweighs the application costs by more for OASI recipients than for the other two groups. Although a higher unemployment rate is likely to increase the probability of applying to SSDI or SSI, the model allows for the effect of the unemployment rate on the disability application decision to be of different magnitudes for those receiving OASI benefits $\left(\beta_{U 2}\right)$, for those not receiving OASI benefits who nevertheless have them readily available $\left(\beta_{U 3}\right)$, and for those who still must wait to claim them $\left(\beta_{U 1}\right)$ (the latter group expected to have the largest marginal effect). As the reduced form model does not account for the probable endogeneity - in this case, unobservable characteristics that affect both one's probability of applying to disability by a particular age and the probability of claiming retirement benefits by that same age - these marginal effects should be interpreted as conditional correlations, rather than causal estimates.

The vector $X$ includes a robust set of individual- and time-specific controls, including potential OASI, SSDI and, where relevant, SSI benefits; the individual's and his or her spouse's earnings in the prior year. Demographic variables consist of gender, race, Hispanic origin, nativity, educational attainment, marital status, and number of children. Economic variables consist of income relative to poverty, real wealth quintiles, work status, industry, occupation, and the availability of defined benefit or defined contribution pension plans. $X$ also includes year dummies, as well as an indicator variable for whether the individual reports a work-limiting

\footnotetext{
${ }^{12}$ OASIRec includes those who receive spousal benefits, but OASIElig looks only at the individual's own age and work experience, as the data only includes eligibility for benefits through the individual's spouse during their SIPP sample window.
} 
disability or a limitation in the Activities of Daily Living module. ${ }^{13}$ Finally, the hazard model also includes a cubic function of the number of months $(\tau)$ since entering the sample (the beginning of each individual's SIPP panel or the month of his $55^{\text {th }}$ birthday, whichever is later), to control for duration dependence.

The observation for individual $i$ in month $t$ is included in the hazard model estimation if $i$ is eligible for either SSDI or SSI in month $t$ and has not yet applied to either program.

Observations are censored at Full Retirement Age (FRA), death, or the end of the merged SSA records in December 2010, whichever is earliest. ${ }^{14}$ When the outcome variable is only SSDI application, observations are also censored in the month of SSI application.

The second empirical model estimates the effect of labor market conditions on the decision to apply for SSDI or SSI among those who are not yet eligible for Social Security retirement benefits. As in the prior model, the individual becomes "at risk" at his $55^{\text {th }}$ birthday or when entering the SIPP sample (whichever is later), and "failure” occurs in the month of SSDI or SSI (or, in an alternative specification, just SSDI) application.

There are several important differences with this model. First, observations are censored at the $62^{\text {nd }}$ birthday, so no individual will be eligible for OASI during the "at-risk” period. Second, because of the focus on whether potential disability applicants are willing to hold out until their $62^{\text {nd }}$ birthdays, the key explanatory variables are a function of the number of months remaining until age 62 and the interaction of months until 62 with the national or state unemployment rate.

The model for this analysis is:

$$
\begin{aligned}
A_{i t}=\Phi\left(\alpha_{0}+\right. & \alpha_{1} \text { URate }_{t}+\theta g(\lambda)+\delta \text { RRate }_{t} \times g(\lambda)+\xi X_{i t}+f\left(\tau_{t}\right) \\
& \left.+v_{i t}\right) .
\end{aligned}
$$

Equation (2) includes the same set of personal, job, and health characteristics and year dummies, $X$, as Equation (1), as well as the same cubic function of time since entering the sample.

\footnotetext{
${ }^{13}$ This variable is equal to one if any individual disability or limitation question is equal to one, encompassing nearly all of the variables used in Dwyer et al. (2001) to simulate the medically-eligible population.

${ }^{14}$ For those born before 1938, the FRA is 65. For each birth year between 1938 and 1943, the FRA increases by 2 months, up to age 66 for those born between 1943 and 1954. Starting with the 1955 birth cohort, the FRA is scheduled to increase by 2 months annually until the 1960 cohort reaches age 67.
} 
Following Meyer (1990), the number of months remaining until one's $62^{\text {nd }}$ birthday, $\lambda$, enters Equation (2) as a spline, $g(\cdot) .{ }^{15}$ The coefficients on each piece of the spline represent the effect on the decision to apply for SSDI or SSI of moving one month closer to the $62^{\text {nd }}$ birthday. This construction forms a spline function that is piecewise continuous and decreasing in the number of months remaining until age 62. If application becomes less likely in the months leading up to one's $62^{\text {nd }}$ birthday, because the potential applicant is holding out for less and less time until Social Security retirement benefits are high enough to meet his needs, then the spline should have a negative marginal effect $(\theta<0)$. If a higher unemployment rate makes holding out without disability application more difficult, then the interaction of the unemployment rate with the spline should have a positive marginal effect $(\delta>0)$.

Finally, the third model addresses a concern that is relevant only after one's $62^{\text {nd }}$ birthday: the potential endogeneity of Social Security retirement claiming in the decision to apply for public disability benefits. Some unobserved characteristics or circumstances may be and likely are - correlated with both the OASI claiming and disability application decisions; for example, disability application rates increase sharply in the month that the individual claims OASI. An instrumental variables (IV) regression requires an instrument that is correlated with receipt of OASI, but uncorrelated with disability application except through OASI claiming.

This study suggests that the spouse's age is such an instrument. There is little doubt in the instrument's strength. Figure 5 indicates that the probability of claiming OASI increases fairly consistently as one's spouse gets older, though the nonlinear pattern suggests including a series of dummy variables - including a dummy equal to one if the individual is unmarried at the time of SIPP sampling - for spouse's age, rather than a continuous variable. ${ }^{16}$ The F-test statistic in the first stage also easily rejects the null of no relationship with OASI claiming. Instrument validity, however, is more difficult to test. Second-stage specifications that include marital status find that married individuals are significantly less likely to apply to a public disability program in a given month. However, when this variable is excluded, the key coefficients are essentially unchanged.

\footnotetext{
${ }^{15}$ The spline is split into nine pieces: 1 to 3 months before the $62^{\text {nd }}$ birthday, 4 to 6 months, 7 to 9 months, 10 to 12 months, 13 to 18 months, 19 to 24 months, 25 to 36 months, 37 to 48 months, and 49 months or more. Formally, the 1-to-3-month piece is equal to $(4-\lambda)$ if $\lambda \leq 3$, and 0 otherwise; the 4-to-6-month piece $=\min (7-\lambda, 3)$ if $\lambda \leq 6$, and 0 otherwise; the 7-to-9-month piece $=\min (10-\lambda, 3)$ if $\lambda \leq 9$, and 0 otherwise; and so on.

${ }^{16}$ The first stage specification that includes spouse's age dummy variables has lower Akaike and Bayesian Information Criteria test statistics than the specification that includes a continuous variable only.
} 
In addition to the prerequisites of the instrument, the nature of the endogenous OASI claiming variable and specification of the model present two challenges. First, OASI receipt is a binary variable, which means that standard two-stage least squares specifications that use linear models in both stages will not be the best fit, especially given that the mean application rate is quite low. An analogous approach for binary endogenous variables is the two-stage residual inclusion model (2SRI), suggested by Rivers and Vuong (1988) and often used by health researchers (see Terza, Bradford, and Dismuke 2007 for a survey). In 2SRI, rather than including predicted values for endogenous variables based on first-stage estimates in lieu of actual values for these variables, the second stage includes both the actual values of the endogenous variables and the residuals from the first stage, the latter of which pick up the bias from the unobserved confounders.

The second challenge is that some specifications include the interaction between the endogenous OASI receipt variable and the exogenous unemployment rate variable. Wooldridge (2002) suggests a two-step procedure. First, I predict the value of the endogenous variable on a first stage that includes the instruments and all of the exogenous variables. Then I use the predicted exogenous variable and the interaction between the predicted value and the exogenous variable as instruments in a standard (linear) IV estimation. ${ }^{17}$

The full IV model for those over age 62, therefore, starts with a first stage:

$$
\text { OASIRec }_{i t}=\Phi\left(\text { SpAge }_{i}, \text { URate }_{t}, \text { SpAge }_{i} \times \text { URate }_{t}, X_{i t}, f\left(\tau_{t}\right)\right),
$$

where $S p A g e_{i}$ is the set of dummies for spouse's age. The predicted value, $O \overline{A S I R} e c_{i t}$, is calculated from the estimates in equation (3). The next step varies by whether the final specification does or does not include interactions between OASI receipt and the unemployment rate. If it does not include the interaction, then a single linear probability model is estimated:

$$
\text { OASIRec }_{i t}=f\left(\text { OASIRec }_{i t}, \text { URate }_{t}, X_{i t}, f\left(\tau_{t}\right)\right)
$$

\footnotetext{
${ }^{17}$ Wooldridge (2002) further suggests including an additional set of instruments: the interaction between the instruments and the exogenous variable that is ultimately interacted with the endogenous variable. Equation (3), therefore, includes $S p A g e_{i}$ and $S p A g e_{i} \times$ URate $_{t}$, and is overidentified.
} 
If the final model does include interactions, then two intermediate linear probability models are estimated:

$$
\begin{gathered}
\text { OASIRec }_{i t}=f\left(\text { OASIRec }_{i t}, \text { URate }_{t}, \text { OASIRec }_{i t} \times \text { URate }_{t}, X_{i t}, f\left(\tau_{t}\right)\right) \\
\text { oASIRec }_{i t} \times \text { URate }_{t}=f\left(\text { o } \widehat{\text { ASIRe }}_{i t}, \text { OASIRec }_{i t} \times \text { URate }_{t}, X_{i t}, f\left(\tau_{t}\right)\right) .
\end{gathered}
$$

where equation (6) does not include $U R$ Rate $e_{t}$ without its interaction with $O A S I R e c_{i t}$ because of collinearity. ${ }^{18}$ The residuals from either (4) or both (5) and (6) are then included in the final specification, which is otherwise similar to equation (2). ${ }^{19}$

Because each regression equation is nonlinear, the results tables report marginal effects that is, the mean derivative of $A_{i t}$ with respect to each variable. Interaction effects - the mean second derivative of $A_{i t}$ with respect to each variable - also account for the nonlinearity (Ai and Norton 2004). Standard errors for the marginal effects in equations (1) and (2) are calculated using the Delta Method. All residuals from the IV estimation are calculated by bootstrap with 100 iterations.

\section{Results}

Figure 1 plots the probability of applying to SSDI, SSI, or either program by age, suggesting how alternative income sources - in particular, Social Security retirement benefits affect the decision to apply for disability benefits. The probability of an SSDI application increases steadily until peaking at age 61 , the last year before most workers become eligible to claim their retirement benefits. Although the SSDI application rate falls substantially between ages 61 and 62, the proportion of 62-year-olds applying for disability remains high, at a rate just below the application rate among 56-year-olds. Application rates, especially for SSI, then fall off quickly.

The application spike just before OASI eligibility suggests that the SSDI application decision depends, at least in part, on the financial resources available to potential applicants. Income availability, from either employment or public welfare programs, often depends on

\footnotetext{
${ }^{18}$ First stage and intermediate stage results are available upon request.

${ }^{19}$ An alternative strategy is to estimate the IV model by maximum likelihood; however, the interaction model did not converge.
} 
macroeconomic conditions. Figure 2 plots SSDI application rates for a broader assortment of age categories, both over time and in comparison to the national unemployment rate. The SSDI application rate has trended upward for most groups over the past two decades, but a cyclical pattern is apparent for most groups, especially for those under age 45 .

Important exceptions are 60-, 61-, and 62-year-olds: while the application rate generally increases with increases in the unemployment rate, SSDI applications among those who are ages 60 to 62 are almost completely uncorrelated with national labor market conditions (Table 2). In addition, the age profile of disability applicants is relatively constant across state unemployment quartiles (Figure 3), albeit with some spikes due to low sample size.

The implication of the acyclicality of disability applications at ages 60 to 62 is that the impending or immediate availability of Social Security retirement benefits - an income source largely buffered from the business cycle - is the main factor in the application decision. Many beneficiaries claim their retirement benefits immediately - as many as 40 to 50 percent within the first three months after turning 62 - and this proportion is highly cyclical (Rutledge and Coe 2012). Some of the effect of an increasing unemployment rate, therefore, will be seen in an increasing proportion of "early claimers" - those who take up retirement benefits between age 62 and their FRA - rather than an increase in disability benefits, at least among those who are eligible for both. Those who are not yet eligible for OASI, however, may find that holding out until 62 becomes more difficult as the unemployment rate climbs, especially if the value of financial assets that provide insurance against income shortfalls decline at the same time. For the same reasons, those who had claimed benefits before their FRA and are receiving monthly benefits lower than their PIA may be more likely to apply for disability benefits to restore their full PIA. The overall lack of response in disability application to an increasing unemployment rate may mask the different responses to the unemployment rate for each OASI group - those who are ineligible, those who are eligible but haven’t yet claimed, and those who are already receiving benefits.

Figure 4 addresses this heterogeneity by OASI status directly, plotting the mean combined application rate for SSDI and SSI by the quartile of the state unemployment rate. ${ }^{20}$

\footnotetext{
${ }^{20}$ The state unemployment quartiles are calculated within calendar months; for example, someone assigned to the first quartile in January 2002 lives in one of the 12-13 states (25 percent of 51 states including D.C.) with the lowest unemployment rate that month. The state unemployment rate quartiles have to be calculated within calendar months to avoid all the fourth quartile (highest unemployment rate) states to come from 2009-2010.
} 
Each group of bars in the graph represents a different OASI group: those who are not yet eligible for retirement benefits, those who are eligible but have not yet claimed, those who are receiving benefits for the first time in the given month, and those who have been receiving benefits for more than a month already. The most obvious finding is that, irrespective of the unemployment rate, many new OASI claimants file for disability benefits in their first month of OASI benefits; the annualized disability application rate in the month of retirement benefit claiming is more than nine times higher on average than for the months prior to the $62^{\text {nd }}$ birthday. ${ }^{21}$ The disability application rate is also substantially lower, by nearly two-thirds, in the months after becoming eligible but before claiming retirement benefits.

The relationship between SSDI application and the unemployment rate within each OASI group is less clear. Individuals not yet eligible for OASI appear to be slightly more likely to apply for SSDI benefits as the unemployment rate increases. The relationship between SSDI application and the unemployment rate is also slightly positive for those who have not yet claimed their available retirement benefits. The trend for the group in the first month of OASI benefits has a general upward slope, but it is non-monotonic. Finally, OASI beneficiaries seem to exhibit no cyclical pattern in their application rates.

To this point, all patterns observed have not controlled for fundamental differences between potential disability applicants across groups by age, benefit availability, or local labor market conditions. Table 3 presents the marginal effects from the hazard model of application to either SSDI or SSI, including controls for personal characteristics, as well as each programs’ potential benefits.

The first specification does not allow for differential responses to the state unemployment rate among those receiving, or eligible for but not yet receiving, Social Security retirement benefits. Compared with the overall average annualized application rate of 1.62 percent, individuals under age 62 are 0.5 percentage points more likely to apply for disability benefits, a statistically significant increase of almost one-third. Individuals 62 and older who have not yet claimed OASI benefits are nearly a full percentage point less likely to apply, a statistically significant decrease of 60 percent from the full-sample average. OASI recipients are essentially right at the full-sample average.

\footnotetext{
${ }^{21}$ Conversations with Social Security personnel indicate that OASI claimants are asked whether they are disabled; if so, their OASI application also becomes an application for SSDI and SSI. The resultant surge in applications from marginal applicants is evident in a surge in denied applications just after age 62.
} 
In the first column, the estimated marginal effect for the state unemployment rate is small and statistically insignificant. The concern here is that this singular marginal effect estimate confounds the varying predicted relationship between the unemployment rate and SSDI application for each of the three groups: OASI ineligibles, OASI beneficiaries, and those who are eligible but have not yet claimed. Indeed, the specification that includes interactions between the OASI status indicators and the state unemployment rate (second column) indicates a more complex relationship, as the response in disability applications to a rising unemployment rate differs substantially by OASI status. ${ }^{22}$ Among older individuals, a rising unemployment rate reinforces the established relationship between disability and OASI claiming: Social Security beneficiaries are increasingly likely to apply for disability benefits, while those who remain working or have otherwise avoided claiming OASI benefits are even less likely to apply to a disability program when the economy weakens. Surprisingly, however, the estimated relationship between disability application and the unemployment rate for individuals age 55 to 61 remains small and statistically insignificant. Overall, the increase in disability applications with the state unemployment rate is statistically significant, but only because of the standard error is slightly smaller.

The results are largely robust to the choice of unemployment rates. The relationship between disability application and the national unemployment rate for each group (third and fourth columns) are similar to the estimates using the state unemployment rate. Finally, including both state and national unemployment rates shows that individuals under age 62 increase their disability applications primarily in response to local labor market conditions, while eligible non-beneficiaries reduce their application probability more in response to the national rate.

Most other estimated marginal effects are in the expected direction. The disability application rate falls with potential retirement benefits and rises with potential SSDI benefits, as expected, though the SSI benefit level has a surprising negative sign. Higher earnings, either from the potential applicant himself or his spouse, reduce the motivation to apply for disability benefits. Applicants are more likely to be male, black, have less than a high school education,

\footnotetext{
${ }^{22}$ The regression includes unemployment rate interacted with the exhaustive set of categorical variables for OASI status, so the model does not include unemployment rate without an interaction. The table, however, shows the marginal effect of the unemployment rate on disability application taking into account all three interactions between unemployment and OASI status, and then each interaction effect.
} 
come from the lowest portions of the income and wealth distributions, or lack health insurance or pension coverage. $^{23}$

Table 4 reports the results from the hazard model where the "failure" is SSDI application. $^{24}$ The results are largely similar to Table 3, with a few exceptions. First, OASI beneficiaries have a significantly higher SSDI application rate than the full sample in the model without interactions, though the marginal effect is insignificant in the interacted model. Second, the state and national unemployment rates in the fifth column both have positive and borderline statistically significant estimates, but the marginal effects are small - a 1 percentage point increase in either unemployment rate increases the annualized SSDI application rate by only 0.05 percentage points. Third, the marginal effects for OASI and SSDI benefits nearly double in magnitude.

Table 5 focuses solely on months when the individuals deciding whether to apply to either SSDI or SSI program are age-ineligible for Social Security retirement benefits. The conceptual framework suggests that disability application is more attractive the further one is from becoming eligible for OASI. Furthermore, an increase in the unemployment rate should lead to more applications, with a declining response to increasing unemployment as one approaches age 62.

However, the estimates presented in Table 5 do not fit this pattern. ${ }^{25}$ The estimated marginal effects for both the state and national unemployment rates are small and statistically insignificant. The point estimates for the spline in the number of months until one's $62^{\text {nd }}$ birthday are also small and statistically insignificant, and they do not exhibit the expected decline in magnitude as the number of months left until OASI eligibility declines. Interacting the spline coefficients with the unemployment rate has little effect on the spline's point estimates, and the interaction effects themselves are small, statistically insignificant, and not at all monotonic.

The only marginal effect in Table 5 that matches the hypothesis is the increase in disability application immediately before one's $62^{\text {nd }}$ birthday. At this point, the disability application has almost no chance to be evaluated before the individual becomes eligible for OASI, so these months essentially function like the months when one is eligible for OASI

\footnotetext{
${ }^{23}$ The estimates for these personal characteristics are not shown in the tables, but are available upon request.

${ }^{24}$ In this specification, SSI application is considered right-censoring, similar to death or reaching FRA.

${ }^{25}$ The estimates for SSDI (analogous to Table 4) are similar to the estimates in Table 5, which consider application to any disability program (analogous to Table 3 ).
} 
benefits, where application rates are higher for those with little to lose by dropping out of the labor force in an effort to get greater benefits.

Table 6 presents the results from the IV model's estimation for person-months starting at age 62, as well as reduced form estimates on this subsample for comparison. Individuals eligible for but not yet receiving OASI benefits have a mean annualized disability application rate of 1.26 percent. ${ }^{26}$ OASI beneficiaries' application rate is 1.7 percentage points higher in the reduced form model, a statistically significant difference. The IV model finds the exact opposite: OASI beneficiaries are far less likely to apply to a public disability program. The residual from the intermediate stage is positive, large, and statistically significant, indicating that unobservable factors that make OASI claiming more likely also make disability application more likely.

Despite the stark difference in the overall application rate for OASI beneficiaries and eligible non-recipients between the reduced form and IV models, the results are largely consistent in the estimated response of the two groups to an economic downturn. When the unemployment rate increases, neither the reduced form nor IV models find a substantial increase in applications for eligible non-recipients, and only one of the four estimates in Table 6 is significantly different from zero. Adding together the unemployment rate marginal effect and its interaction effect with OASI receipt, the reduced form model finds that OASI beneficiaries increase their application rate by about 0.15 percentage points when the unemployment rate rises by one percentage point, and the IV model finds a 0.13 percentage point increase. The residual marginal effect is also statistically insignificant, giving no indication that unobservable factors are correlated in the response to labor market conditions in OASI claiming and disability application.

Finally, Table 7 displays the results from reduced form and IV regressions on the full sample of person-months from age 55 to one's FRA. ${ }^{27}$ Compared to OASI non-recipients over age 62, the IV model without interactions finds that individuals under 62 are 1.3 percentage points more likely to apply for disability benefits, slightly less than the reduced form estimates of

\footnotetext{
${ }^{26}$ To minimize the number of interactions involving the endogenous OASI claiming variable, the estimates in Table 6 include only the OASI beneficiary indicator variable, unlike the specifications in Table 3 with the full set of OASI status categorical variables.

${ }^{27}$ Intermediate-stage residuals are set to zero for person-months before age 62, as OASI claiming is endogenous only for individuals who are eligible for retirement benefits.
} 
1.5. ${ }^{28}$ As in Table 6, OASI beneficiaries switch from 1.2 percentage points more likely than eligible non-recipients in the reduced form model with no interactions to 2.2 percentage points less likely in the IV model, and the residual is again positive and statistically significant. Also like Table 6, both estimation strategies find little response to labor market conditions. The IV marginal effect of the state unemployment rate is slightly positive, with a small additive but not statistically different effect for those under 62, and almost no difference between OASI recipients and non-recipients older than 62. The results in Tables 6 and 7 suggest that, once the model accounts for correlated unobservable factors in the OASI claiming and disability application decisions, the response to an increase in the state unemployment rate is muted, regardless of whether Social Security retirement benefits are available.

\section{Conclusions}

This project examines the interaction between the current or imminent availability of Social Security retirement benefits and applications to public disability programs, and how this relationship differs by national and local labor market conditions. Contrary to existing studies that find a definitive cyclical pattern in disability application, the results indicate that individuals in their early 60s do not apply to SSDI or SSI in substantially greater numbers when the unemployment rate is high.

Both unconditional tabulations and hazard model estimates consistently find that individuals under age 62 do not increase their application rates when the unemployment rate is high, nor do they seem to "hold out" for retirement benefits in any macroeconomic setting. However, the analysis gives conflicting accounts of whether individuals with or without Social Security retirement benefits respond differently to a weak labor market. The reduced form estimates suggest that OASI beneficiaries are more likely to apply to SSDI or SSI, especially in times of high unemployment, while eligible non-recipients are even less likely to apply when the labor market is weak. On the other hand, IV estimates indicate that the increased rate of disability application among OASI beneficiaries may be due to unobservable factors that also make OASI claiming more likely. After accounting for this endogeneity, OASI beneficiaries are

\footnotetext{
${ }^{28}$ Because of the difference in specifications (see note 26), calculating the analogous estimate for the reduced form model requires taking the difference between the Under 62 and Not Yet Claimed OASI marginal effects.
} 
actually less likely to apply than eligible non-recipients, though the model finds no evidence of a response to high unemployment rates by either group.

The lack of cyclicality among older, working-age adults is surprising given that, in aggregate, disability applications increase substantially when the economy is weak (Autor and Duggan 2006). Social Security Administration reports do not disaggregate administrative totals by age of applicant, so corroborating evidence is lacking. The well-established response in longterm benefit programs to short-run macroeconomic fluctuations is a concern to policymakers, but this response appears to be limited to prime-age individuals, rather than those closer to their retirement.

The circumstances of each group of older adults in this analysis suggest some reasons for this lack of cyclicality. Most OASI beneficiaries are already out of the labor force, so when a recession hits, a higher rate of job loss will not affect them. If their financial portfolios and income flows are sufficiently sheltered from macroeconomic fluctuations, then the extra benefit available to them by switching from OASI to SSDI (especially given declining marginal utility of income) may not be worth the cost of application, even though they have already paid the most substantial cost: the requirement of labor force exit.

Individuals who are eligible for Social Security retirement benefits may not have claimed benefits for several reasons. First, their continued work reveals a preference for, and intact ability to perform, their current job. Second, some workers may not have sufficient funds to leave the workforce even with their potential OASI benefit, which makes it difficult to withstand a long potential wait for benefits. Others will have left the labor force already with sufficient retirement savings or pension benefits, so that disability application does not pass the costbenefit tradeoff. Each of these groups would likely fall back on their OASI benefits first, as Social Security provides a readily available, certain income source. But the IV estimates suggest that these individuals do not apply to disability after OASI claiming, even after contact with SSA personnel and educational materials informs them of their potential eligibility.

If individuals in their late 50s and early 60s do not increase disability applications when the unemployment rate increases, is that because they are simply holding on until they can collect retirement benefits? Perhaps. But other results indicate that, despite disability applications peaking at age 61, application prevalence has no detectable relationship with the number of months remaining until one turns 62, once other personal characteristics are taken into 
account. Taken together, these results suggest that the peak in the raw number of applications at age 61 is due mostly to health declines associated with age. In sharp contrast to prime-age adults, there is little evidence that the financial incentives of OASI benefits or the macroeconomic context matter for older individuals. 


\section{References}

Ai, Chunrong and Edward C. Norton. 2003. "Interaction Terms in Logit and Probit Models.” Economic Letters 80: 123-129.

Autor, David H. and Mark G. Duggan. 2006. "The Growth in the Social Security Disability Rolls: A Fiscal Crisis Unfolding.” Journal of Economic Perspectives 20(3): 71-96.

Benitez-Silva, Hugo and Na Yin. 2011. "Disability Insurance Applications near Retirement Age.” State University of New York, Stony Brook working paper.

Bound, John, Todd Stinebrickner, and Timothy Waidmann. 2010. "Health, Economic Resources, and the Work Decision of Older Men.” Journal of Econometrics 156(1): 106-129.

Chirikos, Thomas N. and Gilbert Nestel.1991. "Occupational Differences in the Ability of Men to Delay Retirement.” Journal of Human Resources 26(1): 1-26.

Coe, Norma B., Kelly Haverstick, Alicia H. Munnell, and Anthony Webb. 2011. "What Explains State Variation in SSDI Application Rates?” Working Paper 2011-23. Chestnut Hill, MA: Center for Retirement Research at Boston College.

Coile, Courtney C. and Phillip B. Levine. 2007. "Labor Market Shocks and Retirement: Do Government Programs Matter?” Journal of Public Economics 91(10):1902-1919.

Coile, Courtney and Phillip B. Levine. 2011. "Recessions, Retirement and Social Security.” American Economic Review Papers and Proceedings, 101:3, 23-28.

Dahl, Svenn-Age, Oivind Anti Nilsen, and Kjell Vaage. 2000. "Work or Retirement? Exit Routes for Norwegian Elderly.” Applied Economics 32(14): 1865-1876.

Dwyer, Debra, Jianting Hu, Denton R. Vaughan, and Bernard Wixon. 2001. "Counting the Disabled: Using Survey Self-Reports to Estimate Medical Eligibility for Social Security’s Disability Programs.” ORES Working Paper 90. Washington, DC: Social Security Administration, Office of Policy and Office of Research, Evaluation, and Statistics.

Friedberg, Leora, Michael Owyang, and Anthony Webb. 2008. "Identifying Local Differences in Retirement Patterns.” Working Paper 2008-18. Chestnut Hill, MA: Center for Retirement Research at Boston College.

Hallberg, Daniel. 2008. “Economic Fluctuations and Retirement of Older Employees.” Working Paper 2008-2. Uppsala, Sweden: Institute for Labour Market Policy Evaluation.

Hayward, Mark D., William R. Grady, Melissa A. Hardy, and David Sommers. 1989. “Occupational Influences on Retirement, Disability, and Death.” Demography 26(3): 393-409. 
Meyer, Bruce D. 1990. “Unemployment Insurance and Unemployment Spells.” Econometrica 58(4): 757-782.

Munnell, Alicia H., Mauricio Soto, Robert Triest and Natalia Zhivan. 2008. "How Much do State Economics and Other Characteristics Affect Labor Force Participation of Older Workers?” Working Paper 2008-12. Chestnut Hill, MA: Center for Retirement Research at Boston College.

Riphahn, Regina T. 1997. "Disability Retirement and Unemployment - Substitute Pathways for Labour Force Exit? An Empirical Test for the Case of Germany.” Applied Economics 29(5): 551-561.

Riphahn, Regina T. 1999. "Disability Retirement among German Men in the 1980s.” Industrial and Labor Relations Review 52(4): 628-647.

Rivers, Douglas and Quang H. Vuong. 1988. "Limited Information Estimators and Exogeneity Tests for Simultaneous Probit Models.” Journal of Econometrics 39: 347-366.

Ruhm, Christopher J. 2000. “Are Recessions Good for Your Health?” Quarterly Journal of Economics 115(2): 617-650.

Rutledge, Matthew S. 2011. "The Impact of Unemployment Insurance Extensions on Disability Insurance Application and Allowance Rates.” Working Paper 2011-17. Chestnut Hill, MA: Center for Retirement Research at Boston College

Rutledge, Matthew S. and Norma B. Coe. 2012. "Great Recession-Induced Early Claimers: Who Are They? How Much Do They Lose?” Working Paper 2012-12. Chestnut Hill, MA: Center for Retirement Research at Boston College.

Social Security Administration, Office of the Inspector General. 2008. "Disability Claims Overall Processing Times.” Washington DC: Audit Report A-01-08-18011.

Stapleton, David C., Kevin A. Coleman, Kimberly A. Dietrich, and Gina A. Livermore. 1998. "Econometric Analyses of DI and SSI application and Award Growth.” In Growth in Disability Benefits: Explanations and Policy Implications, edited by Kalman Rupp and David Stapleton, pp. 31-92. Kalamazoo, MI: Upjohn Institute for Employment Research.

Stevens, Ann Huff, Douglas L. Miller, Marianne Page, and Mateusz Filipski. 2011. "The Best of Times, the Worst of Times: Understanding Pro-Cyclical Mortality.” Working Paper.

Strand, Alexander. 2002. "Social Security Disability Programs: Assessing the Variation in Allowance Rates.” ORES Working Paper Series No. 98. Washington, DC: Social Security Administration, Office of Policy and Office of Research, Evaluation, and Statistics. 
Sullivan, Daniel and Till von Wachter. 2009. "Job Displacement and Mortality: An Analysis Using Administrative Data.” Quarterly Journal of Economics 124(3): 1265-1306.

Terza, Joseph V., W. David Bradford, and Clara E. Dismuke. 2007. “The Use of Linear Instrumental Variables Methods in Health Services Research and Health Economics: A Cautionary Note.” Health Services Research 43(3): 1102-1120.

Von Wachter, Till. 2007. "The Effect of Economic Condition on the Employment of Workers Nearing Retirement Age.” Working Paper 2007-25. Chestnut Hill, MA: Center for Retirement Research at Boston College. 
Figure 1. Disability Application Rates by Age

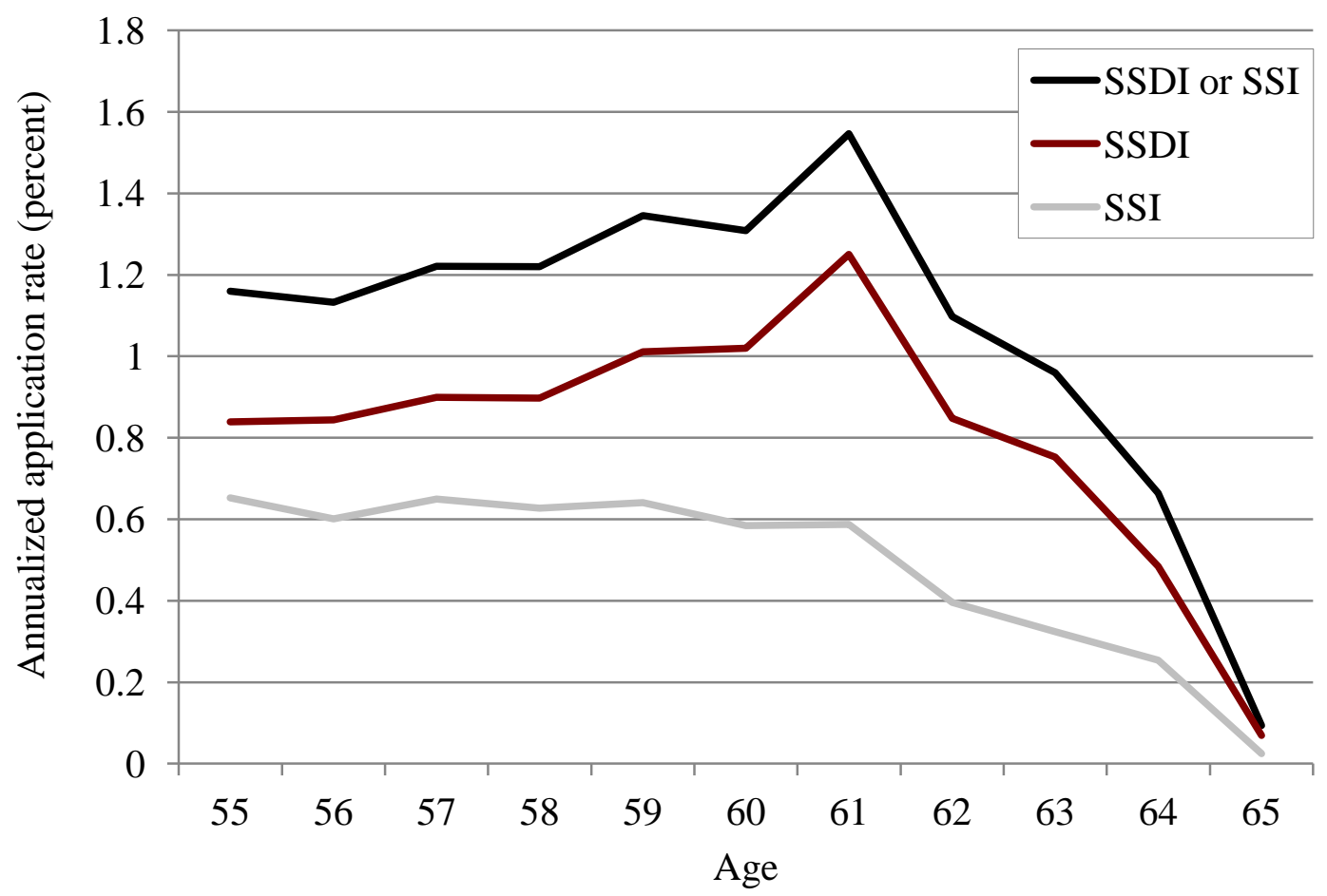

Figure 2. SSDI Application Rates by Age and Over Time

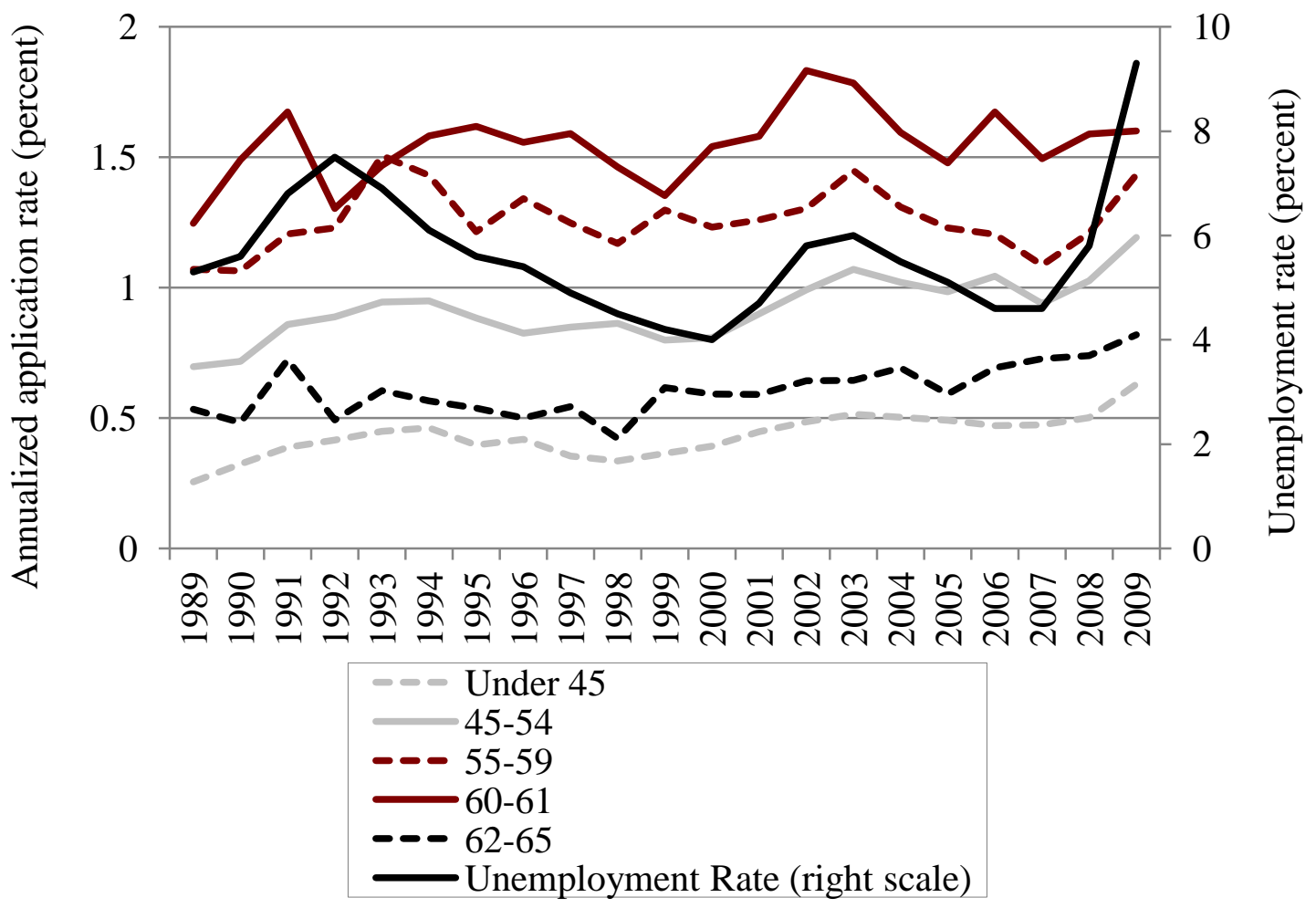


Figure 3. Disability Application Rates by Age and State Unemployment Rate Quartile

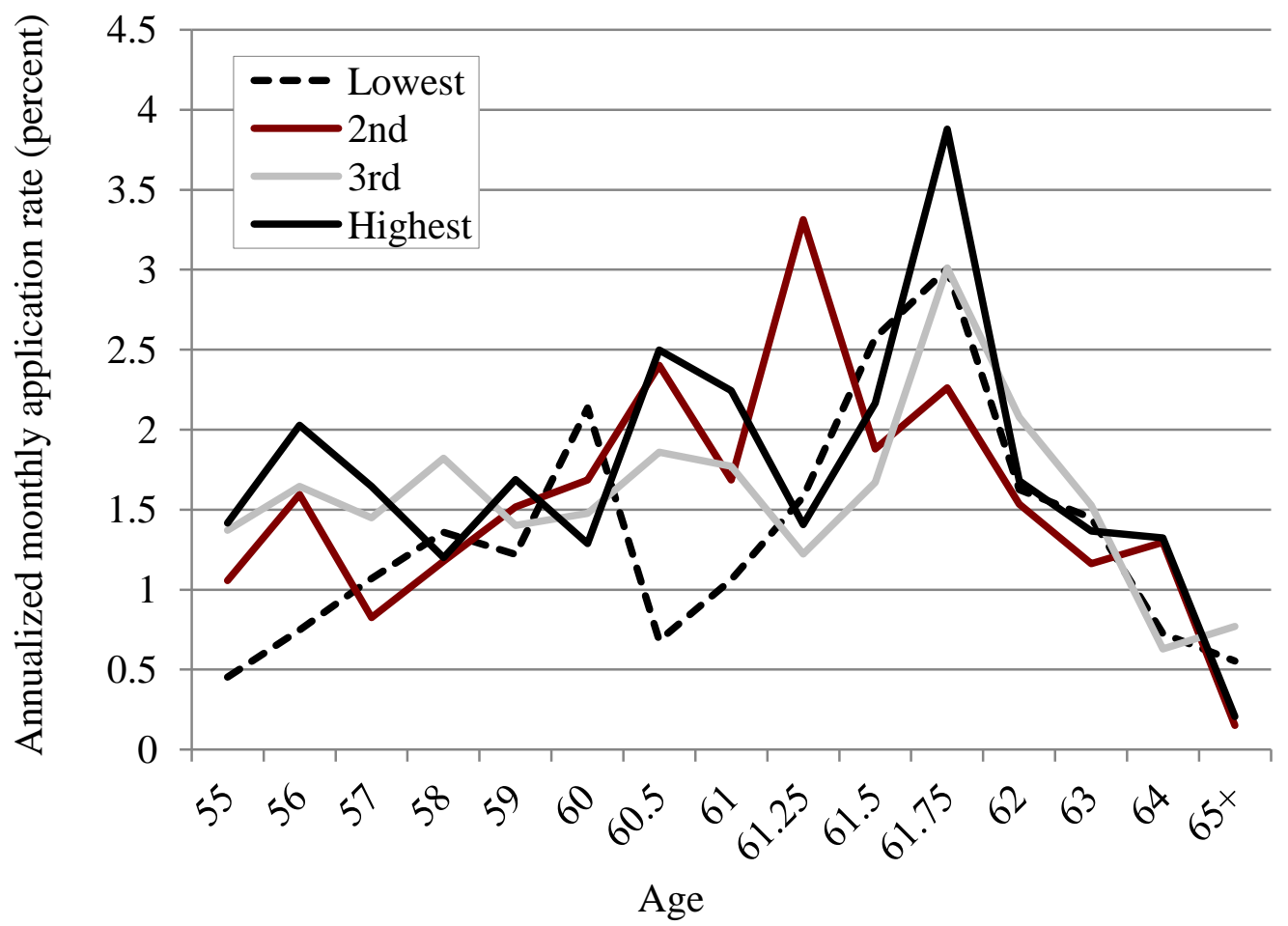

Figure 4. Disability Application Rates by Social Security Retirement Eligibility Status and State Unemployment Rate Quartile

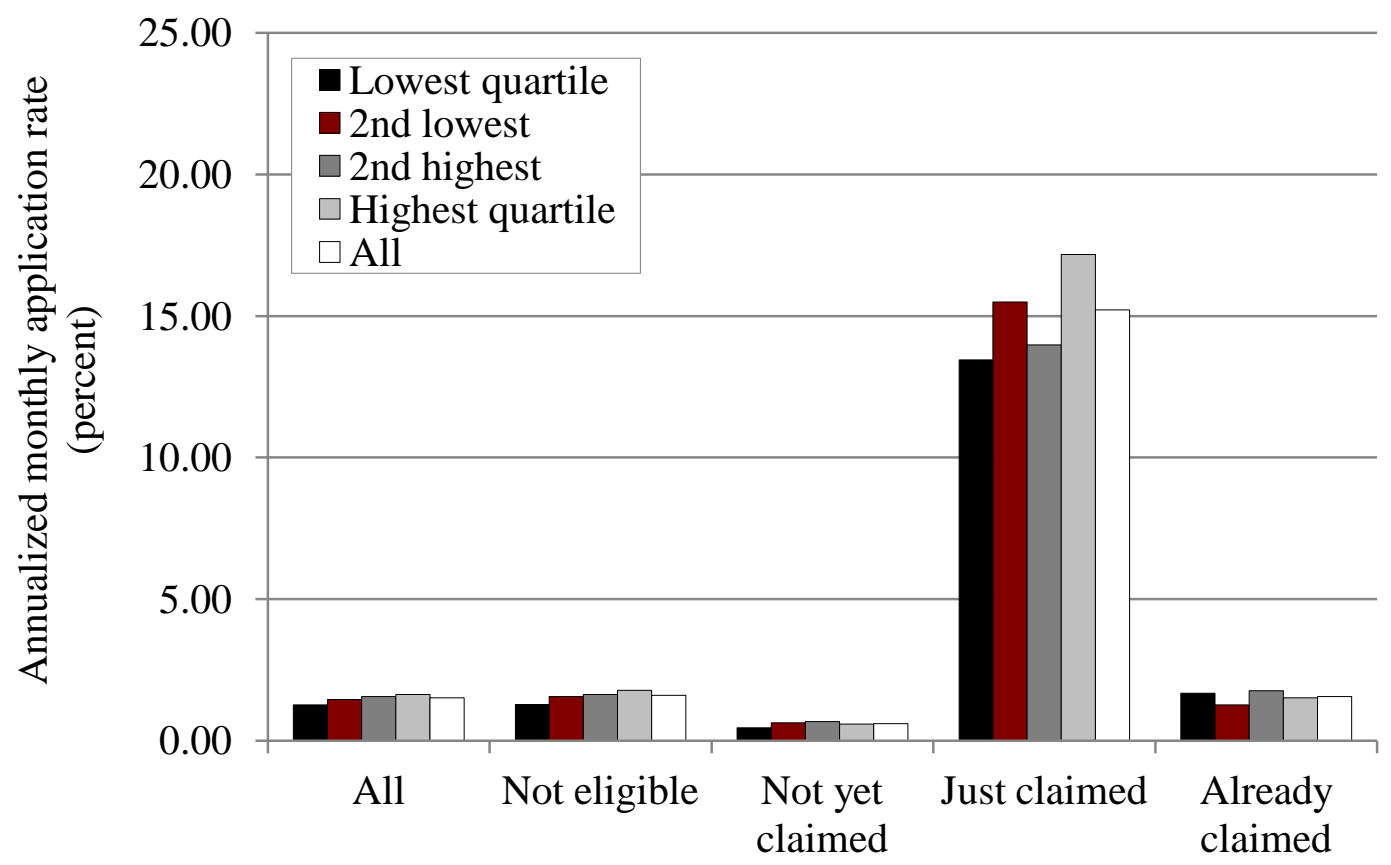

Social Security retirement eligibility status 
Figure 5. Probability of Receiving Social Security Retirement Benefits by Spouse’s Age, Among Those with Own Age 62 and Older

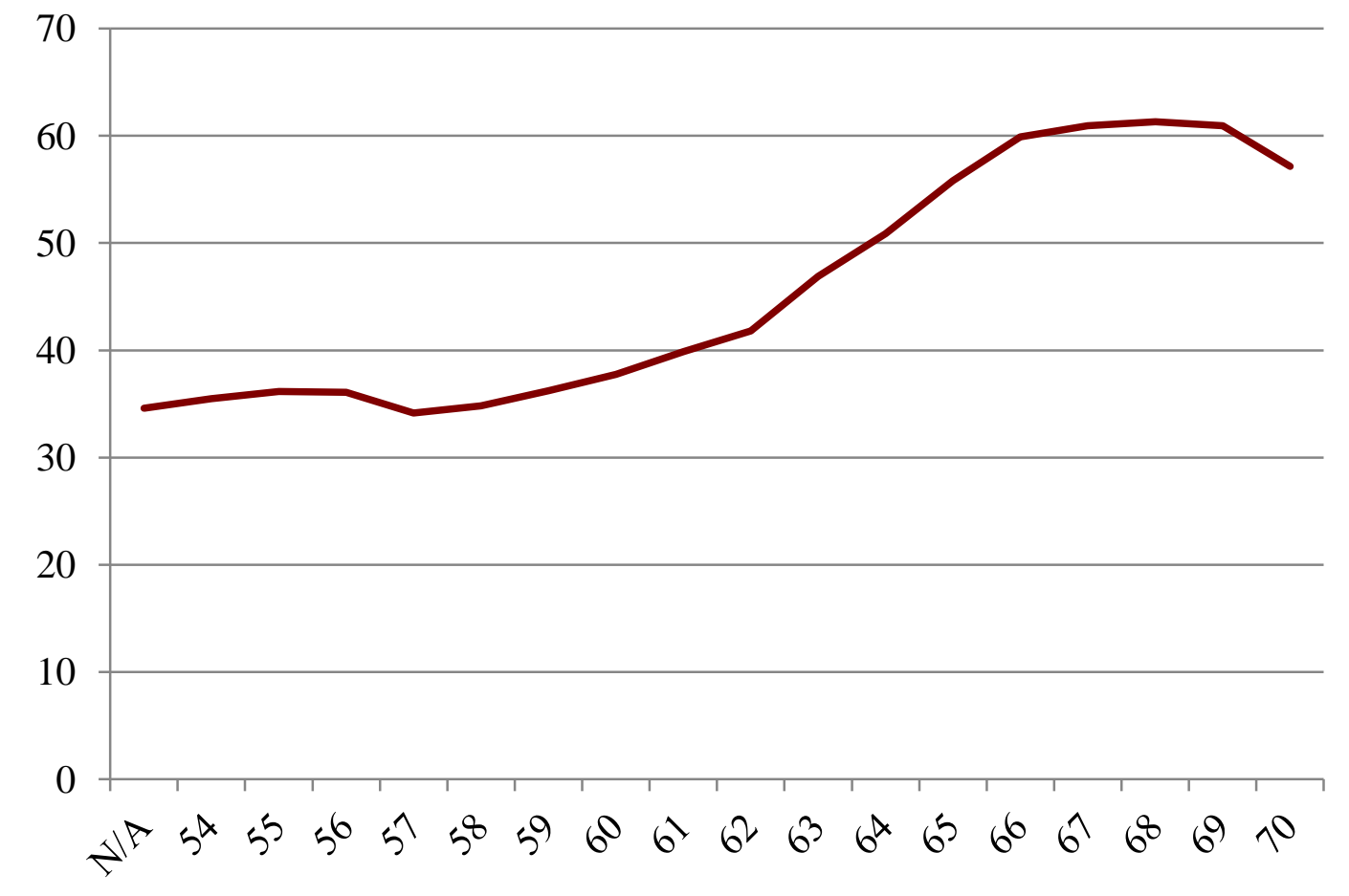


Table 1. Sample Selection Criteria

\begin{tabular}{lr} 
Criterion & Remaining Sample \\
\hline Starting sample & 776,613 \\
Valid SSA match & 578,640 \\
Sampled by SIPP at age 55-61 & 52,552 \\
Reached FRA on or after January 1989 & 51,439 \\
Living in an identifiable state & 43,656 \\
No prior SSDI or SSI application & 39,484 \\
OASI eligible & 34,050 \\
SSDI or SSI eligible & 29,840 \\
& \\
Subsamples: & 29,183 \\
SSDI eligible, all years & 28,994 \\
SSDI or SSI eligible, ever less than age 62 & 28,391 \\
SSDI eligible, ever less than age 62 & 20,869 \\
SSDI or SSI eligible, ever at least age 62 & 20,403 \\
SSDI eligible, ever at least age 62 & \\
\hline
\end{tabular}

Source: Author's calculations from the SIPP Gold Standard File

Table 2. Correlations between the SSDI Application Rate and the National Unemployment Rate, by Age

\begin{tabular}{lr} 
Age Group & $\begin{array}{r}\text { Correlation } \\
\text { Coefficient }\end{array}$ \\
\hline Under 25 & 0.61 \\
$25-34$ & 0.55 \\
$35-44$ & 0.47 \\
$45-54$ & 0.47 \\
$55-59$ & 0.46 \\
$60-61$ & 0.09 \\
62 & 0.03 \\
$63-65$ & 0.40 \\
\hline
\end{tabular}

Source: Author's calculations from the SIPP Gold Standard File 
Table 3. Hazard model marginal and interaction effects for any SSDI or SSI application

\begin{tabular}{|c|c|c|c|c|c|c|}
\hline & $(1)$ & (2) & (3) & (4) & (5) & $(6)$ \\
\hline Mean Application Rate: & & & & & & \\
\hline \multirow[t]{2}{*}{ Under 62} & 0.522 *** & 0.525 * & 0.524 * & 0.472 & 0.524 * & 0.473 \\
\hline & $(0.183)$ & $(0.279)$ & $(0.300)$ & $(0.320)$ & $(0.300)$ & $(0.320)$ \\
\hline \multirow[t]{2}{*}{ Claimed OASI } & 0.192 & 0.014 & 0.191 & -0.044 & 0.190 & -0.044 \\
\hline & $(0.162)$ & $(0.301)$ & $(0.216)$ & $(0.368)$ & $(0.216)$ & $(0.369)$ \\
\hline \multirow[t]{2}{*}{ Not Yet Claimed OASI } & $-0.987 * \star \star *$ & -0.814 *** & -0.988 ** & $-0.720 * *$ & -0.988 ** & -0.718 ** \\
\hline & $(0.238)$ & $(0.274)$ & $(0.467)$ & $(0.313)$ & $(0.467)$ & $(0.314)$ \\
\hline \multirow[t]{2}{*}{ State unemployment rate } & 0.040 & $0.040 * \star$ & & & $0.055 * *$ & 0.042 ** \\
\hline & $(0.026)$ & $(0.020)$ & & & $(0.027)$ & $(0.021)$ \\
\hline \multirow[t]{2}{*}{ National unemployment rate } & & & -0.078 & 0.024 & -0.133 & -0.018 \\
\hline & & & $(0.076)$ & $(0.021)$ & $(0.081)$ & $(\mathrm{N} / \mathrm{A})$ \\
\hline \multirow[t]{2}{*}{ State U Rate $x$ Under 62} & & -0.002 & & & & $0.055 * * *$ \\
\hline & & $(0.035)$ & & & & $(0.020)$ \\
\hline \multirow[t]{2}{*}{ State U Rate $\times$ Claimed OASI } & & 0.069 * & & & & 0.052 \\
\hline & & $(0.039)$ & & & & $(0.042)$ \\
\hline \multirow[t]{2}{*}{ State U Rate $x$ Not Yet Claimed OASI } & & $-0.072 * \star *$ & & & & 0.009 \\
\hline & & $(0.028)$ & & & & $(0.034)$ \\
\hline \multirow[t]{2}{*}{ Nat U Rate $x$ Under 62} & & & & 0.012 & & 0.009 \\
\hline & & & & $(0.038)$ & & $(0.034)$ \\
\hline \multirow[t]{2}{*}{ Nat U Rate $x$ Claimed OASI } & & & & 0.074 & & 0.023 \\
\hline & & & & $(0.046)$ & & $(0.014)$ \\
\hline \multirow[t]{2}{*}{ Nat U Rate $x$ Not Yet Claimed OASI } & & & & $-0.104 * * *$ & & -0.114 *** \\
\hline & & & & $(0.035)$ & & $(0.041)$ \\
\hline $\mathrm{N}$ & $1,973,629$ & $1,973,629$ & $1,973,629$ & $1,973,629$ & $1,973,629$ & $1,973,629$ \\
\hline $\mathrm{R}^{2}$ & 0.065 & 0.065 & 0.065 & 0.065 & 0.065 & 0.065 \\
\hline
\end{tabular}

Note: * significant at $10 \%$; ${ }^{* \star}$ significant at $5 \%$; ${ }^{\star \star \star}$ significant at $1 \%$. Interaction effects (cross-partial derivatives) listed next to interactions. All specifications include benefit levels, previous earnings (own and spouse), personal characteristics, year dummies, and a cubic function of months since entering sample. All estimates are annualized. 
Table 4. Hazard model marginal effects for SSDI application

\begin{tabular}{|c|c|c|c|c|c|c|}
\hline & $(1)$ & $(2)$ & (3) & $(4)$ & $(5)$ & $(6)$ \\
\hline Mean Application Rate: & & & & & & \\
\hline \multirow{2}{*}{ Under 62} & 0.344 * & 0.342 & 0.346 & 0.310 & 0.350 & 0.323 \\
\hline & $(0.189)$ & $(0.295)$ & $(0.296)$ & $(0.345)$ & $(0.295)$ & $(0.346)$ \\
\hline \multirow[t]{2}{*}{ Claimed OASI } & $0.363 * *$ & 0.201 & 0.362 & 0.142 & 0.354 & 0.134 \\
\hline & $(0.185)$ & $(0.332)$ & $(0.249)$ & $(0.408)$ & $(0.246)$ & $(0.407)$ \\
\hline \multirow[t]{2}{*}{ Not Yet Claimed OASI } & $-0.904 * \star \star$ & $-0.745 * \star \star$ & $-0.905 * *$ & -0.661 ** & -0.904 ** & -0.660 ** \\
\hline & $(0.235)$ & $(0.282)$ & $(0.447)$ & $(0.324)$ & $(0.447)$ & $(0.326)$ \\
\hline \multirow[t]{2}{*}{ State unemployment rate } & 0.048 * & 0.048 ** & & & $0.063 * *$ & 0.050 ** \\
\hline & $(0.026)$ & $(0.020)$ & & & $(0.027)$ & $(0.021)$ \\
\hline \multirow[t]{2}{*}{ National unemployment rate } & & & -0.067 & 0.038 * & $0.060 * *$ & $0.047 * *$ \\
\hline & & & $(0.077)$ & $(0.022)$ & $(0.028)$ & $(0.022)$ \\
\hline \multirow[t]{2}{*}{ State U Rate $x$ Under 62} & & -0.003 & & & & 0.030 \\
\hline & & $(0.035)$ & & & & $(0.019)$ \\
\hline \multirow[t]{2}{*}{ State U Rate $\times$ Claimed OASI } & & 0.073 * & & & & 0.041 \\
\hline & & $(0.040)$ & & & & $(0.040)$ \\
\hline \multirow[t]{2}{*}{ State U Rate $x$ Not Yet Claimed OASI } & & $-0.073 * \star \star$ & & & & 0.001 \\
\hline & & $(0.028)$ & & & & $(0.033)$ \\
\hline \multirow[t]{2}{*}{ Nat U Rate x Under 62} & & & & 0.007 & & 0.001 \\
\hline & & & & $(0.040)$ & & $(0.033)$ \\
\hline \multirow[t]{2}{*}{ Nat U Rate x Claimed OASI } & & & & 0.083 * & & 0.048 *** \\
\hline & & & & $(0.049)$ & & $(0.016)$ \\
\hline \multirow[t]{2}{*}{ Nat U Rate x Not Yet Claimed OASI } & & & & $-0.103 * \star \star$ & & $-0.102 * * *$ \\
\hline & & & & $(0.034)$ & & $(0.037)$ \\
\hline $\mathrm{N}$ & $1,973,629$ & $1,973,629$ & $1,973,629$ & $1,973,629$ & $1,973,629$ & $1,973,629$ \\
\hline $\mathrm{R}^{2}$ & 0.065 & 0.065 & 0.065 & 0.065 & 0.066 & 0.067 \\
\hline
\end{tabular}

Note: * significant at 10\%; ** significant at 5\%; ** significant at 1\%. Interaction effects (cross-partial derivatives) listed next to interactions. All specifications include benefit levels, previous earnings (own and spouse), personal characteristics, year dummies, and a cubic function of months since entering sample. All estimates are annualized. 
Table 5. Hazard model marginal effects for any SSDI or SSI application before age 62

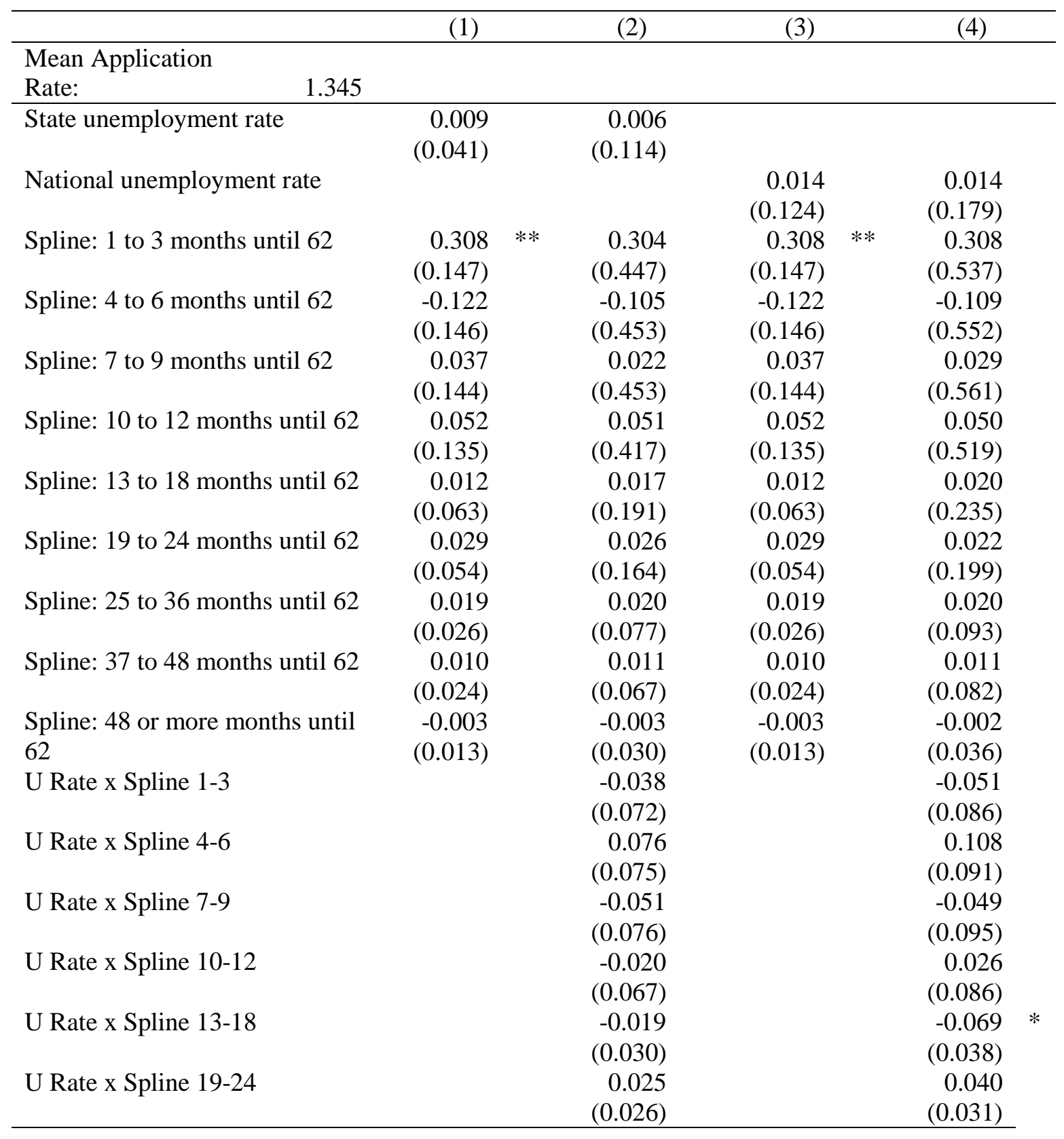


Table 5. Hazard model marginal effects for any SSDI or SSI application before age 62 (cont’d)

\begin{tabular}{|c|c|c|c|c|}
\hline & (1) & (2) & (3) & (4) \\
\hline \multirow[t]{2}{*}{ U Rate x Spline 25-36 } & & 0.003 & & 0.002 \\
\hline & & $(0.012)$ & & $(0.015)$ \\
\hline \multirow[t]{2}{*}{ U Rate x Spline 37-48 } & & -0.009 & & -0.001 \\
\hline & & $(0.011)$ & & $(0.013)$ \\
\hline \multirow[t]{2}{*}{ U Rate x Spline 49+ } & & 0.006 & & 0.006 \\
\hline & & $(0.005)$ & & $(0.006)$ \\
\hline $\mathrm{N}$ & 589,049 & 589,049 & 589,049 & 589,049 \\
\hline $\mathrm{R}^{2}$ & 0.089 & 0.089 & 0.089 & 0.089 \\
\hline
\end{tabular}

Note: * significant at $10 \%$; ** significant at $5 \%$; *** significant at $1 \%$. Interaction effects (cross-partial derivatives) listed next to interactions. All specifications include benefit levels, previous earnings (own and spouse), personal characteristics, year dummies, and a cubic function of months since entering sample. All estimates are annualized.

Table 6. Instrumental variables and reduced form hazard model marginal effects for any SSDI or SSI application, 62 and older

\begin{tabular}{|c|c|c|c|c|c|c|c|c|c|}
\hline \multirow{2}{*}{ Mean Application Rate: } & \multirow{2}{*}{$\begin{array}{c}1.26 \\
0\end{array}$} & \multicolumn{4}{|c|}{ Reduced Form } & \multicolumn{4}{|c|}{ Instrumental Variables } \\
\hline & & \multicolumn{2}{|c|}{ (1) } & \multicolumn{2}{|l|}{ (2) } & \multicolumn{2}{|c|}{ (3) } & \multicolumn{2}{|c|}{$(4)$} \\
\hline \multirow{2}{*}{\multicolumn{2}{|c|}{ Claimed OASI }} & & $* *$ & & $* *$ & & & & $* *$ \\
\hline & & $\begin{array}{r}1.725 \\
(0.209)\end{array}$ & $*$ & $\begin{array}{r}1.744 \\
(0.560)\end{array}$ & $*$ & $\begin{array}{r}-2.074 \\
(0.982)\end{array}$ & $* *$ & $\begin{array}{r}-2.020 \\
(0.748)\end{array}$ & $*$ \\
\hline \multirow{2}{*}{\multicolumn{2}{|c|}{ Claimed OASI Residual }} & & & & & & $* *$ & & $* *$ \\
\hline & & & & & & $\begin{array}{r}3.299 \\
(0.496)\end{array}$ & $*$ & $\begin{array}{r}3.058 \\
(0.773)\end{array}$ & $*$ \\
\hline \multicolumn{2}{|l|}{ State unemployment rate } & $\begin{array}{r}0.053 \\
(0.040)\end{array}$ & & $\begin{array}{r}-0.041 \\
(0.053)\end{array}$ & & $\begin{array}{r}0.066 \\
(0.040)\end{array}$ & $*$ & $\begin{array}{r}0.059 \\
(0.045)\end{array}$ & \\
\hline \multicolumn{2}{|c|}{ State U Rate x Claimed OASI } & & & $\begin{array}{r}0.193 \\
(0.095)\end{array}$ & $* *$ & & & $\begin{array}{r}0.072 \\
(0.128)\end{array}$ & \\
\hline \multirow{3}{*}{\multicolumn{2}{|c|}{ Residual }} & & & & & & & 0.036 & \\
\hline & & & & & & & & $(0.115)$ & \\
\hline & & 643,87 & & 643,87 & & 643,87 & & 643,87 & \\
\hline $\mathrm{N}$ & & 4 & & 4 & & 4 & & 4 & \\
\hline
\end{tabular}

Note: * significant at $10 \%$; $* *$ significant at $5 \%$; ${ }^{* * *}$ significant at $1 \%$. Interaction effects (cross-partial derivatives) listed next to interactions. All specifications include benefit levels, previous earnings (own and spouse), personal characteristics, year dummies, and a cubic function of months since entering sample. All estimates are annualized. 
Table 7. Instrumental variables and reduced form hazard model marginal effects for any SSDI or SSI application

\begin{tabular}{|c|c|c|c|c|c|c|c|}
\hline \multirow{2}{*}{$\begin{array}{c}\text { Mean Application } \\
\text { Rate: }\end{array}$} & \multicolumn{3}{|c|}{ Reduced Form } & \multicolumn{4}{|c|}{ Instrumental Variables } \\
\hline & (1) & $(2)$ & & (3) & & $(4)$ & \\
\hline Under 62 & & & & & $* *$ & & $* *$ \\
\hline & $\begin{array}{r}0.522 \\
(0.183)\end{array}$ & $\begin{array}{r}0.525 \\
(0.279)\end{array}$ & & $\begin{array}{r}1.283 \\
(0.269)\end{array}$ & $*$ & $\begin{array}{r}1.295 \\
(0.270)\end{array}$ & $*$ \\
\hline Claimed OASI & & & & & $* *$ & & $* *$ \\
\hline & $\begin{array}{r}0.192 \\
(0.162)\end{array}$ & $\begin{array}{r}0.014 \\
(0.301)\end{array}$ & & $\begin{array}{r}-2.154 \\
(0.199)\end{array}$ & $*$ & $\begin{array}{r}-2.158 \\
(0.174)\end{array}$ & $*$ \\
\hline Not Yet Claimed OASI & $\begin{array}{r}-0.987 \\
(0.238)\end{array}$ & $\begin{array}{r}-0.814 \\
(0.274)\end{array}$ & & & & & \\
\hline Claimed OASI Residual & & & & & $* *$ & & $* *$ \\
\hline & & & & $\begin{array}{r}4.820 \\
(0.344)\end{array}$ & $*$ & $\begin{array}{r}3.929 \\
(0.819)\end{array}$ & $*$ \\
\hline State unemployment rate & $\begin{array}{r}0.040 \\
(0.026)\end{array}$ & $\begin{array}{r}0.040 \\
(0.020)\end{array}$ & $* *$ & $\begin{array}{r}0.043 \\
(0.023)\end{array}$ & $*$ & $\begin{array}{r}0.034 \\
(0.026)\end{array}$ & \\
\hline State U Rate x Under 62 & & $\begin{array}{r}-0.002 \\
(0.035)\end{array}$ & & & & $\begin{array}{r}0.063 \\
(0.047)\end{array}$ & \\
\hline $\begin{array}{l}\text { State U Rate x Claimed } \\
\text { OASI }\end{array}$ & & $\begin{array}{r}0.069 \\
(0.039)\end{array}$ & $*$ & & & $\begin{array}{r}-0.006 \\
(0.031)\end{array}$ & \\
\hline State U Rate x Not Yet & & & $* *$ & & & & \\
\hline Claimed OASI & & $\begin{array}{r}-0.072 \\
(0.028)\end{array}$ & $*$ & & & & \\
\hline $\begin{array}{l}\text { U Rate x Claimed OASI } \\
\text { Residual }\end{array}$ & & & & & & $\begin{array}{r}0.152 \\
(0.122)\end{array}$ & \\
\hline $\mathrm{N}$ & $\begin{array}{r}1,887,50 \\
3\end{array}$ & $\begin{array}{r}1,887,50 \\
3\end{array}$ & & $\begin{array}{r}1,887,50 \\
3\end{array}$ & & $\begin{array}{r}1,887,50 \\
3\end{array}$ & \\
\hline
\end{tabular}

Note: $*$ significant at $10 \%$; ** significant at $5 \%$; *** significant at $1 \%$. Interaction effects (cross-partial derivatives) listed next to interactions. All specifications include benefit levels, previous earnings (own and spouse), personal characteristics, year dummies, and a cubic function of months since entering sample. All estimates are annualized. 


\section{RECENT WORKING PAPERS FROM THE CENTER FOR RETIREMENT RESEARCH AT BOSTON COLLEGE}

Automatic Enrollment, Employee Compensation, and Retirement Security

Barbara A. Butrica and Nadia S. Karamcheva, November 2012

401(k) Participant Behavior in a Volatile Economy

Barbara A. Butrica and Karen E. Smith, November 2012

Immigrant Networks and the Take-Up of Disability Programs: Evidence from U.S. Census Data Delia Furtado and Nikolaos Theodoropoulos, October 2012

Growth in Health Consumption and Its Implications for Financing OASDI: An International Perspective

Barry P. Bosworth and Gary Burtless, September 2012

Using Participant Data to Improve 401(k) Asset Allocation

Zhenyu Li and Anthony Webb, September 2012

Job Demand and Early Retirement

Sepideh Modrek and Mark R. Cullen, August 2012

Changes in Labor Force Participation of Older Americans and Their Pension Structures: A Policy Perspective

Frank W. Heiland and Zhe Li, July 2012

How Would GASB Proposals Affect State and Local Pension Reporting?

Alicia H. Munnell, Jean-Pierre Aubry, Joshua Hurwitz and Laura Quinby, June 2012

Borrow Less Tomorrow: Behavioral Approaches to Debt Reduction

Dean Karlan and Jonathan Zinman, May 2012

Spousal Labor Market Effects from Government Health Insurance: Evidence from A Veterans Affairs Expansion

Melissa A. Boyle and Joanna N. Lahey, April 2012

All working papers are available on the Center for Retirement Research website (http://crr.bc.edu) and can be requested by e-mail (crr@bc.edu) or phone (617-552-1762). 